\title{
Desenvolvimento do Self Dialógico nos Primeiros Anos de Vida: Teoria e Pesquisas
}

\author{
Mónica Roncancio Moreno \\ Pontificia Universidad Javeriana \\ Angela Maria Uchoa Branco \\ Universidade de Brasília
}

\begin{abstract}
RESUMO - O presente artigo discute algumas das pesquisas recentes sobre o desenvolvimento do Self dialógico nos primeiros anos de vida. Revisamos os estudos publicados que tinham como fundamento teórico a emergência do Self. Identificamos que existe um rápido crescimento de pesquisas com bebês, contudo, pesquisas em fases iniciais de alfabetização são praticamente ausentes, a lacuna mais significativa se estende dos 4 aos 6 anos. Encontramos, ainda, que o modelo adulto da Teoria do Self Dialógico tenta ser adaptado para crianças, mas esse modelo precisa de transformações para dar conta dos processos de desenvolvimento do Self. Concluímos que, para a realização de pesquisas com crianças, seja incluída a análise microgenética de interações sociais das crianças em contextos específicos, com vistas ao estudo da emergência de seus processos de desenvolvimento.
\end{abstract}

Palavras-chave:Teoria do Self Dialógico, desenvolvimento, emergência

\section{Dialogical Self Development in Early Life: Theory and Research}

\begin{abstract}
This article discusses some recent studies on the development of the dialogical self during the first years of life. We reviewed published studies that had the emergence of self as a theoretical basis. We identified an increasing number of studies with babies. However, studies realized during the early stages of literacy are absent, and the most significant gap extends from 4- to-6-year-old children. We found that there are attempts to adapt the adult model of the Dialogical Self Theory for children, but this model needs to change to account for processes of the development of self. We conclude by arguing that there is a need for microgenetic analysis of children's social interactions within specific contexts, in order to study the emergence of their development processes.
\end{abstract}

Keywords: Dialogical Self Theory, development, emergence

A Teoria do Self Dialógico (TSD) proposta por Hermans e colaboradores (Hermans, 2001; Hermans \& HermansKonopka, 2010) tem tido um especial impacto na psicologia de hoje. Em vários países, incluindo o Brasil, diversos grupos de pesquisa trabalham ativamente na construção de um corpus empírico e teórico que permita ampliar o panorama da área (Lima DeSouza, Oliveira, DaSilveira, \& Gomes, 2013; Lopes de Oliveira, 2013; Simão, 2010). Em língua portuguesa, verificamos a produção de pesquisadores brasileiros (Branco \& Madureira, 2008; Lyra, 2010; Mattos \& Chaves, 2013) e portugueses (Cunha, Salgado,\& Gonçalves, 2012; Gonçalves \& Ribeiro, 2012; Rosa \& Gonçalves, 2013; Salgado \& Gonçalves, 2007). O interesse pelo tema vem promovendo, desde 2012, significativo intercâmbio sob a forma de Grupo de Trabalho de Psicologia Dialógica da Associação Nacional de Pesquisa e Pós-Graduação em Psicologia (ANPEPP). Destacamos, de início, a publicação de livros seminais,como The Dialogical Self: Meaning as Movement (Hermans\&Kempen, 1993) e Dialogical Self Theory: Positioning and Counter-Positioning in a Globalizing Society (Hermans \& Hermans-Konopka, 2010). Recentemente, um número especial da revista Interacções (2013), publicado em Portugal, em língua inglesa, reuniu alguns importantes avanços teóricos da psicologia dialógica.

1 Endereço para correspondência: Pontificia Universidad Javeriana Facultad de Psicología, Carrera 5a, no. 39-00, Edificio 95, Manuel Briceño Jauregui, S. J. Oficina 215., Bogotá, Colombia. E-mail:
Considerando a relevância do tema e o fato de a literatura em português ser ainda restrita (Santos \& Gomes, 2010), o presente artigo tem por objetivo abordar a Teoria do Self Dialógico (Hermans, 2001; Hermans \& Hermans-Konopka, 2010) na interface com a psicologia do desenvolvimento humano de caráter cultural (Bertau, 2012; Bertau \& Gonçalves, 2007; Fogel, Koeyer, Bellagamba, \& Bell, 2002; Lyra, 2007). Não pretendemos, no entanto, apresentar uma revisão da literatura sobre a temática do self dialógico, mas sim descrever e discutir concepções e elaborações teóricas acerca do desenvolvimento do self dialógico na infância, com base na psicologia dialógica. Para tanto, será dada ênfase ao contexto das relações dialógicas construídas pela criança, desde o nascimento até, aproximadamente, os 7 anos de vida.

A Teoria do Self Dialógico tem sido desenvolvida, principalmente, com base na narrativa de adultos, mas, nos últimos 10 anos, a literatura mostra um substancial incremento do estudo destes estudos durante os primeiros anos de vida (Bertau \& Gonçalves, 2007; Bertau, Gonçalves \& Ragatt, 2012; Garvey \& Fogel, 2007; Lyra, 2007, 2010). É por isso que consideramos fundamental discutir o que se tem produzido na investigação de crianças,em seus primeiros anos de vida, com relação à emergência do Self dialógico.

Na primeira parte do texto, apresentamos uma visão geral, mas não exaustiva, da Teoria do Self Dialógico. Na segunda parte, fazemos referência a pesquisas que abordam o tema por idades, desde o nascimento até os 2 anos, e desde os 2 anos até os 7, destacando os conceitos centrais que contribuem para o estudo da emergência do Self nos primeiros anos de vida. 


\section{Teoria do Self Dialógico: Conceitos e Fundamentos Teóricos}

A Teoria do Self Dialógico (TSD) proposta por Hermans e colegas surge da síntese das ideias de George Mead, William James e Mikhail Bakhtin. Na literatura, existem diversas definições sobre o Self (Andacht \& Michel, 2005; Bennett $\&$ Sani, 2004; Komatsu, 2012), mas, no presente texto, nos centramos na proposta de Hermans (2001). Com base nesse autor, definimos o Self como uma multiplicidade dinâmica de posições de Eu, relativamente autônomas, as quais têm a possibilidade de se mobilizarem de uma posição espacial para outra, de acordo com as mudanças no tempo e no contexto de inserção do sujeito. O Selfé plural, polifônico e dialógico, e as posições de Eu emergem como consequência de uma tensão dinâmica gerada por relações sociais significativas (Hermans, 2001). Sendo assim, o Self não é apenas um "Eu", mas múltiplos "Eus" que coexistem em um sistema de caráter dialógico. Essas posições, em contínuo diálogo, podem ser inferidas a partir das múltiplas vozes presentes nas narrativas do sujeito.

É comum, na literatura, a inerente confusão entre Self como um todo e Self como somente sua dimensão reflexiva, e, para evitar tal confusão, usaremos o Self com maiúscula para designar o sistema composto pelo "I/self", e o self com minúscula para designar apenas a dimensão reflexiva. $\mathrm{Na}$ unidade "I/self" o " $T$ " (ou 'Eu') é a dimensão do agente no sistema e o self, a dimensão reflexiva, conceitualização inspirada em G. H. Mead (1934). Assim, neste artigo, quando falamos de Self, estamos falando de uma unidade "I/self", na qual ação e reflexão são partes dessa mesma unidade (Branco, 2010).

Hermans (2001) defende que "o Eu (I) flutua através de diferentes posições, inclusive opostas, e tem a capacidade imaginativa de dotar cada posição com uma voz e, assim, são estabelecidas as relações entre posições" (p. 248). A partir das mobilizações das posições em espaços imaginários, são produzidos campos dinâmicos, nos quais múltiplos sentidos se constroem. Nesses campos, acontecem diferentes selfnegociações, self-contradições e self-integrações (Hermans, 2001). As posições de Eu são tanto internas, quanto externas, e funcionam de uma maneira relativamente autônoma. As posições internas são do tipo Eu-como-mãe, Eu-comoesposa, Eu-como-boa aluna. Já as posições externas são experimentadas como parte do ambiente, e consideradas, pelo indivíduo, relevantes desde a perspectiva das posições internas. Posições internas e externas coexistem como posições de Eu no sistema de Self, e formam parte de um ambiente concebido como "meu", habitado por pessoas e objetos significativos. Portanto, diferentes "Eus" podem se mover no espaço, de acordo com a situação e o tempo. No presente texto, sempre que fizermos referência ao Self, estaremos falando do Self dialógico conceitualizado pela TSD.

Desde uma perspectiva ontogenética, são as trocas entre o indivíduo e o mundo que vão permitir o desenvolvimento do Self. O Self do indivíduo emerge das relações que este indivíduo estabelece com o social e, segundo Bertau et al. (2012), o Self apenas existe se está relacionado a outros "selves".

\section{Emergência e Desenvolvimento do Self Dialógico nos Primeiros 24 Meses de Vida}

Os estudos na área do desenvolvimento do Self dialógico nos primeiros dois anos de vida são relativamente recentes (Bertau et al., 2012; Bertau \& Gonçalves, 2007; Fogel et al., 2002; Lyra, 2007; Trevarthen, 2012). O foco dos pesquisadores varia desde a compreensão do papel da musicalidade dos bebês como prática cultural (Trevarthen, 2012), até as conquistas de aspectos específicos do desenvolvimento do infante na interação com os adultos, levando em consideração a dialogicidade e a capacidade de estabelecer relações com outros. A dialogicidade é uma característica do sistema do Self dialógico que, segundo Bertau e Gonçalves (2007), "existe desde o início da vida, inclusive anterior a este momento, no qual as pessoas constroem sentido sobre a vida do bebê; a dialogicidade não poderia se desenvolver, nem existir, sem os outros sociais orientados em direção à pessoa" (p. 9). Quando a criança vem ao mundo, já existe um espaço sociocultural esperando por ela e, nesse espaço, serão negociados sentidos e significados ao longo do curso de vida. Assim, a dialogicidade consiste na característica inerente ao sistema de Self dialógico, que é imerso na cultura em que o bebê está envolvido desde antes do nascimento, em especial, nos diálogos estabelecidos entre os adultos em seus contextos culturais.

Os autores aqui destacados pesquisam, especificamente, os processos de emergência do Self dialógico, do nascimento aos 24 meses de idade, ressaltando a importância das relações sociais dialógicas na construção do sistema do Self. São eles: Alan Fogel, Marie-Cécile Bertau, Maria Lyra, Philippe Rochat, entre outros.

\section{Frames como padrões recorrentes de interação social e o desenvolvimento do Self dialógico}

Fogel et al. (2002) iniciam a discussão com duas perguntas: existe o Self dialógico desde os primeiros dias de vida? Será que seu desenvolvimento se dá de forma sistemática? Essas perguntas instigam a investigação das relações dialógicas desde o nascimento e a identificação dos processos construtivos de comunicação cada vez mais complexos. Os autores consideram que os conceitos de comunicação, Self e cultura são categorias profundamente integradas, cada qual se desenvolvendo em relação à outra, e que, além disso, o desenvolvimento se dá com a participação ativa do sujeito em processos dinâmicos de constante comunicação com os outros (Fogel, 1993).

Assumindo a proposta da perspectiva dialógica de Hermans e outros, Fogel e colaboradores (Fogel, 1993; Fogel et al., 2002) acreditam na progressiva configuração de diferentes posições de Eu desde os primeiros meses de vida. O desenvolvimento do Self dialógico ocorre através de inovações criativas, durante diálogos (trocas dialógicas) interpessoais que dão origem ao Self, e, posteriormente, através de diálogos intrapessoais. Assim, Fogel considera que existe uma forma de Self não verbal, que aparece na primeira infância. Esse Self emerge no relacionamento com os outros e antecede a linguagem na ontogênese. 
Para sustentar essa ideia, o autor propõe a existência de frames, definidos como padrões recorrentes de relação social que facilitam o desenvolvimento do Self dialógico: "o self dialógico se desenvolve a partir de frames nos quais acontece mútua criatividade, pois nestes momentos é quando as posições de Eu se destacam devido a um processo social ou intrapessoal dialógico" (Fogel et al., 2002, p. 202). Os frames são padrões sociais ou rotinas correguladas e recorrentes, tais como jogos sociais, conflitos padronizados, saudações e despedidas, nos quais as crianças estão envolvidas desde muito cedo. Esses padrões sociais podem ser criativos ou rígidos e, em ambos os casos, o sujeito pode assumir uma determinada posição de Eu. Portanto, os frames se constituem em oportunidades dialógicas para as crianças explorarem suas posições de Eu em relação a outros (Bertau et al., 2012).

Os frames podem ser capturados na interação mãebebê, a partir de análises microgenéticas (Branco, 2012). Dessa forma, na sociogênese do Self dialógico, a criança apresenta indicadores de "consciência do Self" (olhares, experiências proprioceptivas), que são descritos por pesquisadores no âmbito dos estudos sobre interação mãe-bebê. Segundo as análises de Fogel et al. (2002), nos primeiros 6 meses de vida, os bebês começam a coordenar suas experiências proprioceptivas. Tais experiências vão lhes permitir, por exemplo, perceber as mãos como elemento visual "pertencente" a seu Self: "a experiência psicológica da criança sobre a mão, desde uma perspectiva táctil e proprioceptiva, é uma posição de Eu" (Fogel et al. 2002, p. 194). Ainda que o uso do termo "posição de Eu" para se referir aos posicionamentos do bebê pareça estar relacionado a um Self já formado, ou a uma dimensão mais cognitiva, Fogel et al. (2002) esclarecem que esses posicionamentos são sensoriais:

O termo "posição de Eu" para a criança pequena é a experiência que tem o bebê de cada uma dessas múltiplas modalidades sensoriais que compõem o seu mundo. Informações dos olhos, ouvidos, nariz, boca e membros criam um diálogo que é único desde a perspectiva individual da criança. Ela é um leque de estímulos sensoriais. Cada novidade na experiência sensorial interage com um espectro co-criativo e vibrante (pp.195-196).

Assegurar que a criança, desde os primeiros meses de vida, tenha diversas posições de Eu pode parecer uma afirmação perigosa. É claro que reconhecemos as diversas conquistas do bebê nos primeiros meses de vida, e a pesquisa empírica tem nos mostrado os primórdios da dialogicidade, no entanto, acreditamos ser ainda necessário demonstrar, de alguma maneira, como possíveis funcionamentos incipientes estariam relacionados a protótipos de posições de $\mathrm{Eu}$, ao longo do desenvolvimento do Self na criança.

Concordando com os estudos anteriormente citados, Garvey e Fogel (2007) destacam o desenvolvimento das emoções na emergência do Self dialógico. As emoções são definidas como "experiências dialógicas do corpo" (Garvey \& Fogel, 2007, p. 51), que se comunicam com outro(s) corpo(s) de uma maneira corregulada. As emoções e as relações se constituem de forma mútua e dinâmica através do tempo e, especificamente, as emoções funcionam como um indicador de posicionamentos incorporados (Fogel \& Garvey,
2007). Uma maneira de estudar a emergência do Self poderia ser focada na compreensão das emoções nos primórdios da comunicação, presentes nas interações mãe-bebê, e com base nas significações que emergem dos padrões de interação social presentes na comunicação mãe-bebê.

Retomando o conceito de frames comunicativos (criativos ou rígidos), os estudos de Garvey e Fogel (2007) integram as elaborações teóricas relacionadas à emergência do Self, a teoria dos sistemas dinâmicos e as ideias de autores como Wallon, Bakhtin e Bohm. Garvey e Fogel (2007) analisam a comunicação de emoções em três frames específicos: (1) brincadeira social; (2) interesse por brinquedos; e (3) assimetria emocional. Utilizando a abordagem microgenética, os pesquisadores observaram as variações presentes na comunicação emocional. Esta comunicação foi denominada "variabilidade familiar" (familiar variability), e evidencia nuances e inovações na dinâmica dos relacionamentos. A "variabilidade familiar" permite aos participantes da troca comunicativa "reconhecer os padrões significativos da comunicação emocional que compõem o pano de fundo do relacionamento" (Garvey \& Fogel, 2007, p.70).Dessa maneira, a "variabilidade familiar" permite o estabelecimento de uma base sobre a qual as contribuições da criança para a manutenção e interrupção do diálogo são destacadas pelo adulto, para facilitar a sua (da criança) diferenciação de si. Nos frames comunicativos, é evidente que a criança, ao mesmo tempo em que se conecta com o outro, comece a se diferenciar. Esse fato também foi destacado por Bertau (2004) como uma questão paradoxal, pois a criança participa, progressivamente, de um mundo social compartilhado e, ao mesmo tempo, se distancia no sentido de um mundo próprio. A criança começa, portanto, a assumir diferentes posicionamentos pessoais com relação a sua mãe, determinados pelas convergências e divergências nas trocas comunicativas, e, nessa interação, emergem inovações que permitem a diferenciação de si por parte da criança.

Outros estudos, seguindo a linha dos argumentos de Fogel et al. (2002), propõem que as origens do Self dialógico se encontram em algumas experiências perceptuais básicas, que permitem a diferenciação do próprio corpo em relação ao mundo circundante (Rochat, 2003).

\section{Origens do $\operatorname{Self}$ na diferenciação perceptual do bebê}

Rochat (2003) assume que existe uma "diferenciação do Self" desde os primeiros dias do nascimento do bebê. No choro e na coordenação dos movimentos do corpo com a visão, o bebê poderia perceber alguma coisa que ninguém mais percebe: "O bebê parece captar informação sistemática de seu próprio corpo como uma entidade diferenciada, uma entidade que é experienciada como algo diferente de outros corpos físicos ou objetos que estão no ambiente" (Rochat, 2003, p. 723). Progressivamente, o bebê começa a desenvolver uma consciência de Self (self-awareness) e aquela consciência que inicialmente era perceptual (corpo em ação) transforma-se em um sentido de Self avaliativo. Rochat (2003) considera essa consciência de Self como um processo dinâmico, e propõe cinco níveis para seu desenvolvimento ao 
longo do curso de vida. No nível 0 (confusão), o indivíduo não é consciente de qualquer reflexo no espelho, assim, não é consciente de si próprio. No nível 1 (diferenciação), o indivíduo é consciente do espelho, ele já tem um sentido de que o que é percebido no espelho é diferente do que é percebido no mundo circundante. No nível 2 (situação), o indivíduo já relaciona a experiência de seu próprio corpo com a imagem do espelho. O sujeito é capaz de explorar sistematicamente o vínculo entre os movimentos observados no espelho e aquilo que é percebido proprioceptivamente. No nível 3 (identificação), o indivíduo manifesta reconhecimento dele mesmo, distingue aquele no espelho como "Eu" e não como outro sujeito. No nível 4 (permanência), o Self é identificado além do aqui e agora, além da experiência no espelho. No nível 5 (meta-consciência do Self), "o self é reconhecido não apenas desde a perspectiva da primeira pessoa, mas também desde a terceira pessoa. Os indivíduos não só são conscientes deles mesmos, mas também de como eles são na mente de outros" (Rochat, 2003, p. 722).

Esses níveis ou estados de consciência do Self são dinâmicos e flutuantes, e oscilam permanentemente ao longo da vida. A criança de aproximadamente 4 ou 5 anos, em geral, já alcançou o nível cinco, ou seja, já é consciente dela mesma e de como os outros pensam sobre ela.

Ainda sobre esse tema, recentemente,Hermans e Hermans-Konopka (2010) retomaram pesquisas de diferentes autores (Fogel et al., 2002; Maratos, 1973; Meltzoff \& Moore, 1994; Nagy \& Molnar, 2004; Rochat, 2003, entre outros) para sustentar as origens do Self dialógico. Os autores concordam que existem posicionamentos de Eu desde os primeiros meses de vida e, em apoio a esse pressuposto, retomam como recurso empírico pesquisas sobre imitação, sorriso, protrusão da língua e "provocação". Nesses estudos, a provocação está relacionada com a capacidade da criança para gerar gestos espontâneos e esperar uma resposta do pesquisador. Segundo os autores, "a natureza incorporada do self dialógico é expressa muito cedo em processos de posicionamento e reposicionamento, e a sua natureza social está enraizada nas formas pré-linguísticas e não verbais de interação" (Hermans \& Hermans-Konopka, 2010, p. 200). Essas formas de interação são do tipo imitação, sorriso e outras condutas sociais apresentadas pelo bebê nos seus relacionamentos com adultos. Assim, existiriam "precursores" das posições de Eu desde muito cedo, sendo possível identificar a existência de algumas posições mais dominantes do que outras.

Hermans e Hermans-Konopka (2010) destacam a existência de posições de Eu desde os primeiros dias de vida, o problema é que a base teórica para tais pressupostos deriva da própria teoria do Self Dialógico, que foi desenvolvida a partir da investigação com adultos. Além disso, a utilização de evidências empíricas, advindas de pesquisas que adotaram pressupostos epistemológicos totalmente distintos, não garante coerência às elaborações teóricas tecidas sobre tais evidências.

Para nós, entretanto, fica claro que os autores citados por Hermans e Hermans-Konopka (2010) partem de perspectivas divergentes sobre o desenvolvimento infantil. Sendo assim, a menção dos resultados dessas pesquisas para sustentar as bases da teoria dialógica torna-se um recurso questionável. Supomos que a ausência de pesquisas empíricas com crianças pequenas acabou por levar os autores a realizar inferências problemáticas. A maioria das análises feitas por Hermans e Hermans-Konopka (2010) indica uma tentativa de ajustar a teoria adulta do Self Dialógico para também explicar o desenvolvimento do bebê, sem que haja uma verdadeira reflexão sobre o que, realmente, pode ocorrer nos primeiros anos de vida. Os autores parecem desconsiderar a dinâmica e imprevisibilidade dos processos de desenvolvimento humano (Valsiner, 2007). Vemos aqui, portanto, lacunas que indicam a necessidade de realizar pesquisas que se ocupem de enriquecer o corpus empírico dos processos subjacentes ao desenvolvimento do Self dialógico em bebês e crianças pequenas.

Bertau $(2004,2007,2012)$ realiza estudos que fornecem luzes para a compreensão da dialogicidade, enfatizando o conceito de voz, próprio das origens da psicologia dialógica.

\section{Vozes na construção da dialogicidade}

Muitas das pesquisas que sustentam a TSD se ocupam da análise da dialogicidade, dos posicionamentos emergentes e da produção de vozes na vida adulta (Gonçalves \& Ribeiro, 2012; Hermans, 2003), no entanto, uma visão ontogenética dessas posições e vozes requer mais investigações e elaboração teórica. Bertau (2004, 2007, 2012) apela para uma visão que conceitua o desenvolvimento do Self dialógico nos primeiros meses de vida, propondo que as primeiras experiências sensoriais no interior das formas dialógicas dão origem aos construtos de Self e de símbolo (Gratier \& Bertau, 2012).A dialogicidade existe desde o nascimento dos indivíduos (ou antes disso) e continua se desenvolvendo nas práticas socioculturais e na interação mãe-bebê. Assim, antes de existir um Self dialógico, existe a dialogicidade.

A dialogicidade pode ser identificada nas interações sociais do bebê, um participante ativo na construção de processos dialógicos manifestos em ações orientadas à socialização, tais como sorriso e outros gestos sociais. É justamente nessa direção que os adultos começam a atribuir sentido aos gestos do bebê e a lhe atribuir intencionalidade (ainda difusa), que são interpretados como convites ao diálogo. O ponto que permite afirmar que, realmente, as ações da criança são dialógicas é o momento no qual o bebê assume um lugar ativo nos diálogos com o adulto. Quando o adulto entende que está sendo convidado pelo bebê e o diálogo é iniciado, temos aí uma situação dialógica (Bertau, 2004).

Esses diálogos acontecem nos ritmos e rotinas socioculturais que se iniciam com a voz social da mãe. Progressivamente, a criança vai participando dos processos comuns de socialização, identificando as regularidades de sua cultura especifica, as quais vão favorecer a emergência do Self imerso na cultura. Esses ritmos e rotinas permitem a troca entre a criança e o mundo social, resultando no desenvolvimento de relacionamentos em nível emocional e cognitivo (Bertau, 2004).

Assim como outros autores, Bertau também assinala que existe uma mudança substancial no desenvolvimento do Self aos 9 meses de idade (Hermans \& Hermans-Konopka, 2010; Lyra, 2006; Rochat, 2003; Tomasello, 1993; Wallon, 1987). Essa mudança acontece por conta da atenção partilhada, que 
leva a criança a assumir a perspectiva do outro. A atenção partilhada é gerada a partir da inclusão de um objeto na interação com o adulto. Aproximadamente aos 9 meses, a relação diádica criança-adulto passa a ser triádica, criançaadulto-objeto. Esse objeto também pode ser uma situação de interesse para a criança (Rodriguez, 2006). Assim, a criança começa a ver os outros como intencionais nas interações sociais, e a ver os objetos a partir da perspectiva do outro. Por exemplo, em uma situação em que a criança participa de uma conversa com um adulto, quando o adulto aponta o dedo em direção a um objeto, o bebê compreende que não é o dedo que deve ser observado, mas sim o objeto para o qual o dedo aponta. Nesse momento, a criança compreende a diferenciação entre objetos do entorno, adultos e seus comportamentos. Tanto a inclusão do objeto na interação, quanto assumir a perspectiva do outro permitem a emergência da "atenção autoreflexiva" (Tomasello, 1993). Portanto, a atenção autorreflexiva é considerada uma conquista fundamental para o desenvolvimento do Self dialógico (Bertau, 2004).

As "vozes" no sistema de Self emergem na relação dialógica com o adulto, a partir de dois elementos: dialogicidade e troca. Inicialmente, quando a mãe fala, é ela que assume todas as vozes, estabelecendo, assim, um modelo de troca e dialogicidade com a criança. Dessa maneira, a criança aprende como e quando assumir um papel com significado. Esse papel encontra-se vinculado a uma estrutura suposta na relação com a mãe, mas, progressivamente, é possível que ele se torne um papel verdadeiro, em termos de uma posição relacionada a uma perspectiva ativamente assumida pela criança, segundo Bertau (2004):

Primeiro existe uma estrutura de voz exterior percebida, com a qual a criança pode concretamente se alinhar, e, em seguida, sentir e experienciar a estrutura como sendo cada vez mais própria e mais significativa para o self, bem como para o outro e para a troca mútua. A voz dupla da mãe é um convite para a criança assumir uma das vozes como um papel na conversação, e, ao mesmo tempo, demonstra que uma pessoa pode falar e agir com mais do que uma voz (p.33).

O certo é que a voz da mãe é fundamental para o desenvolvimento do Self dialógico, e outros autores, como Fogel et al. (2002), concordam com esta afirmação. Mas onde a voz está localizada? Essa voz não se encontra nem na pessoa, nem na cultura, ela emerge na zona de contato entre pessoa-cultura e não é uma entidade fixa (Bertau, 2007, 2012). A noção de voz é caracterizada por sua multiplicidade, mas principalmente por sua independência e agencialidade.

Concluindo o pensamento da autora, a partir de sua perspectiva é possível afirmar que o Self emerge com certas experiências dialógicas, e a criança, progressivamente, desenvolve, mediante o processo de internalização, uma multiplicidade de posições dialógicas internas e externas. Essas posições emergem nas interações com outros, desde muito cedo no desenvolvimento. As vozes expressas por posições imaginadas pela mãe aparecem em diálogos cotidianos, que permitem ao bebê reconhecê-las e internalizálas para, posteriormente, desenvolver suas próprias vozes. A noção de voz, portanto, é um aspecto central da teoria do
Self dialógico, pois se encontra relacionada ao processo de mudança no desenvolvimento de novas e diferentes posições de Eu.

Outros estudos focam,particularmente,na comunicação e no estabelecimento de padrões de interação (Lyra, 2006, 2007) para a emergência do Self. Os estudos de Lyra (2006, 2007) propõem o modelo teórico denominado Estabelecimento, Extensão e Abreviação (EEA).

\section{Modelo estabelecimento, extensão e abreviação (EEA)}

Lyra (2006, 2007, 2010) propôs o Modelo EEA para estudar a emergência e o desenvolvimento da comunicação mãe-bebê, e do Self dialógico. Retomando a proposta teórica dos Sistemas Dinâmicos e o dialogismo de Bakhtin, a autora defende um desenvolvimento humano histórico, único e criativo, no qual o sujeito é construtor ativo de sua identidade (Lyra, 2006). No decorrer de seu trabalho, a autora estabelece como aspecto central a ideia de uma "realidade virtual",que "existe paralela à nossa capacidade sensorial, como uma ampliação e transformação desta, na qual emerge e se constitui o Self. Esta 'realidade virtual' representa os primórdios da nossa capacidade semiótica ou simbólica" (Lyra, 2007, p. 88). Segundo a autora, a emergência do Self é gerada pela diferenciação que a criança faz nos seus posicionamentos,durante o diálogo com o adulto.

Dentro do quadro de referência adotado pela autora, encontram-se os conceitos fundamentais da Teoria dos Sistemas Dinâmicos (Thelen \& Smith, 1994). Nessa teoria, princípios básicos como auto-organização, atratores, emergência do novo e períodos de estabilidade e mudança instauram-se no coração da proposta. As contribuições da teoria dialógica focalizam-se em duas considerações: "na existência de um único lugar-no tempo e no espaçopossível de ser ocupado pelo sujeito e a característica de responsividade" (Lyra, 2007, p. 90).

Especificamente, o "Modelo EEA propõe que o processo de comunicação mãe-bebê seja construído obedecendo a uma sequência de padrões organizacionais que se distinguem pelas diferentes características das trocas mãe-bebê" (Lyra, 2007, p. 90). Existem, assim, alguns processos subjacentes ao desenvolvimento do sistema de comunicação mãe-bebê, que destacam, à maneira de figura-fundo, uma atividade de recorte definida por Lyra como "dinâmica dialógica de recorte".

Os componentes do Modelo EEA são o estabelecimento, extensão e abreviação, e eles emergem, historicamente, como padrões de interação na troca comunicativa mãe-bebê, com ou sem a mediação de um objeto. Esses padrões emergem nos oito primeiros meses de vida, permitindo novos níveis organizacionais de comunicação, caracterizados por períodos de quase-estabilidade. Assim, o desenvolvimento humano é construído através de diversos, e cada vez mais complexos, níveis de organização nos sistemas relacionais. Duas características interessantes são colocadas pela proposta: (1) a dialogicidade existe previamente em qualquer linguagem (pois existe um sistema simbólico já construído, que circunda o bebê); e (2) a história da humanidade só é concretizada a partir da relação comunicativa. $\mathrm{Na}$ relação, acontecem as 
trocas comunicativas entre os participantes da interação. Portanto, a interação mãe-bebê tem uma história própria e é orientada pelas especificidades de cada troca comunicativa. Tanto os valores da cultura, quanto as orientações da família são considerados aspectos chave da proposta.

A contribuição de Lyra revela um panorama que remete à integração de duas teorias que reconhecem os processos envolvidos no desenvolvimento e nadialogicidade como elementos centrais na emergência do Self. O corpus empírico construído pela autora amplia as possibilidades de compreender como nas primeiras interações do bebê com o mundo começam a se organizar sistemas de relações, que constituem a base para o desenvolvimento do Self. A visão da autora apresenta mais nuances quanto a questões relacionadas aos possíveis 'posicionamentos' iniciais do bebê e o desenvolvimento de I-positions, mencionados por outros autores neste artigo. $\mathrm{O}$ certo é que seu minucioso trabalho de pesquisa acaba fortalecendo os pressupostos de que a dialogicidade existe antes do início da vida e que as trocas comunicativas e os padrões de interação são condição sine qua non para o desenvolvimento do Self dialógico.

\section{Panorama dos estudos sobre os primeiros 2 anos de vida}

O corpus empírico dos estudos sobre o desenvolvimento do Self dialógico antes dos 2 anos tem se enriquecido recentemente. Desde a criação da TSD, muitos pesquisadores na área de desenvolvimento humano tentam descobrir quais os primórdios da dialogicidade e dos conceitos centrais da teoria, como, por exemplo, "posicionamentos de Eu". As vantagens da maioria das pesquisas nessa faixa etária centram-se em considerar os aspectos socioculturais das análises sobre a emergência e desenvolvimento do Self dialógico (Bertau, 2004, 2012; Fogel et al., 2002; Garvey \& Fogel, 2007; Lyra, 2007). Esse "Self" contextualizado, estudado na interação com a mãe, e os aspectos da comunicação relacionados a ele permitem ter uma visão integral e complexa do desenvolvimento.

Acreditamos que é um desafio estudar o bebê e, como já mencionamos anteriormente, existem alguns estudos em que prevalece uma visão adulta da criança (Hermans \& HermansKonopka, 2010). As capacidades do bebê são analisadas em função da TSD, desenvolvida com base e dados sobre adultos, na tentativa de se ajustar conceitos, como "posições de Eu", às primeiras conquistas do bebê. Os indicadores mais frequentes, utilizados nesses trabalhos para estudar o bebê, relacionam-se ao sorriso, protrusão da língua, olhar, e outras ações emergentes na relação com o adulto cuidador (Hermans \& Hermans-Konopka, 2010). Esses indicadores têm sido utilizados, tradicionalmente, em pesquisas realizadas, de diversas posições teóricas, não necessariamente dialógicas, que buscam demonstrar as capacidades precoces do bebê. Sendo assim, seria necessário realizar novas pesquisas que relacionem esses indicadores ao desenvolvimento do Self dialógico, não sendo indicado utilizar pesquisas de outros paradigmas para se concluir sobre a emergência do Self, segundo uma perspectiva dialógica.
Do nosso ponto de vista, consideramos que o desenvolvimento do Self dialógico é gerado em um espaço histórico e culturalmente situado, questão que é retomada pela maioria dos autores aqui apresentados. Mesmo sem partir de um embasamento inatista, assumimos que o bebê chega ao mundo com um equipamento biológico, ou com algumas pré-disposições importantes que lhe permitam discriminar estímulos do ambiente para conseguir sobreviver. Com esse equipamento, o bebê se aproxima do mundo social e, na interação com os outros, começa a se diferenciar, sempre se constituindo na cultura. Em nossa análise, portanto, concluímos que, na interação com o outro, a criança consegue coordenar a sua experiência proprioceptiva para se diferenciar do universo em geral. Esse Self corresponderia a um sentido de si difuso, que se configura, em primeiro lugar, no corpo do bebê, em função da experiência dialógica com o cuidador. Esse sentido de si é inicialmente corporal, mas serve de base para o processo progressivo de diferenciação de si. Por exemplo, quando a criança começa a perceber sua mão como mão - o que só acontece pela cultura e pelo desenvolvimento semiótico - isso vai se incorporar no sentido de si, mas não em um sentido de Self mais amplo, ou de posicionamento de Eu nos moldes propostos por Hermans (Hermans \& Hermans-Konopka, 2010). Logo, pesquisas com bebês podem evidenciar processos de diferenciação de si, mas não necessariamente posicionamentos de Eu.

A seguir, apresentamos algumas das pesquisas analisadas com relação ao desenvolvimento do Self dos 2 aos 7 anos.

\section{Desenvolvimento do Self dos Dois aos Sete Anos}

De acordo com a revisão da literatura realizada, podemos afirmar que evidências empíricas sobre o desenvolvimento do Self dialógico dos 2 aos 7 anos é muito escassa, conquanto existam estudos que, embora não se referenciem diretamente ao Self dialógico, apresentam análises sobre o Self. Pesquisas com participantes de 2 e 3 anos são praticamente ausentes. Já pesquisas realizadas com crianças com maior desenvolvimento da linguagem falada focalizamse na narrativa (Bellgard, 2005; Uszynska-Jarmoc, 2008). Pesquisas sobre memória autobiográfica também ocupam um lugar privilegiado no campo de estudo (Nelson, 1992), mas esses estudos não serão abordados neste artigo.

Autores como Hermans e Hermans-Konopka (2010), em suas análises, retomam estudos da teoria da mente, para sugerir como acontece o desenvolvimento do Self dialógico nessa faixa etária. Harter (1999), por sua vez, embasa-se no desenvolvimento do Self, a partir da perspectiva piagetiana. Desde uma perspectiva sociocultural, Komatsu (2012) apresenta uma visão mais dinâmica, que ele denomina como "Self presentacional". Assim, para oferecer um panorama geral da pesquisa nessa faixa etária, analisamos as propostas a seguir.

Harter (1999) assegura que a emergência e o desenvolvimento do Self são gerados a partir de uma construção cognitiva e social. Segundo sua proposta, a linguagem e as capacidades representacionais estão na base dessa construção. A autora analisa as diferenças nas representações do Self em diferentes idades, e afirma 
que dos 2 aos 4 anos as crianças só podem construir representações cognitivas concretas de caraterísticas observáveis do Self. Assim, é possível escutar de crianças dessa idade verbalizações, como "Eu sei o alfabeto, eu posso contar, eu moro numa casa grande". Dessa maneira, as autorrepresentações estão ainda muito vinculadas ao comportamento da criança.

Para Harter (1999), as crianças nessa idade (2 aos 4) "ainda não representam categorias conceituais de ordem superior através das quais o self é definido, e este [o self] se encontra ligado às suas preferências. As autodescrições estão diretamente ligadas às caraterísticas observadas por outros" (Harter, 1999, p. 37).

Já crianças de 5 a 7 anos, segundo Harter (1999), têm capacidades cognitivas que vão lhes permitir maiores habilidades de autodescrição. Verbalizações para definir seus próprios talentos atléticos, habilidades sociais e cognitivas são comuns nessa idade, contudo, é recorrente encontrar polarização de conceitos opostos, tais como bem ou mal, ou seja, a criança se situa a partir do tudo ou nada, do bom ou ruim, não existindo espaços intermediários.

A autora considera que o conceito de autoestima (alta e baixa autoestima) pode ser pesquisado a partir de questionários preenchidos pelos professores das crianças. Esses conceitos seriam expressos, pelas crianças, através de comportamentos que demonstrem confiança, curiosidade, iniciativa e independência. Pesquisar a autoestima por meio de pessoas mais próximas às crianças permitiria, segundo ela, coletar informação privilegiada que, talvez, um pesquisador externo não fosse capaz. A autora desenvolveu um questionário padrão para pais e professores, visando obter informações sobre a autoestima da criança. A proposta de Harter (1999), portanto, apresenta grande ênfase em capacidades cognitivas e representacionais para o desenvolvimento do Self. Observamos, ainda, de acordo com a perspectiva da autora, a necessidade do uso de testes para a avaliação de conceitos, como autoestima nas crianças pequenas.

Do nosso ponto de vista, o desenvolvimento cognitivo é importante para permitir a elaboração de avaliações de si mesmo, no entanto, acreditamos que não é o desenvolvimento cognitivo que determina essas avaliações, uma vez que consideramos central o papel da afetividade e das emoções nos processos do desenvolvimento do Self (Freire, 2008; Rocancio-Moreno, 2015; Rocancio-Moreno \& Branco, 2014; Valsiner, 2007).

Os estudos de Komatsu $(2010,2012)$ estão focados em uma perspectiva relacional e discursiva, cujo conceito fundamental é o de "Self presentacional". O Self Presentacional é um tipo de Self que "emerge na configuração das conversas da criança com os outros, e que cria um significado único para o observador" (Komatsu, 2010, p. 209). Para isso, o autor retoma conceitos da proposta de pesquisadores como Harré e outros, que enfocam, principalmente, a construção de relações e identidade. $\mathrm{O}$ autor se embasa, ainda, nos postulados de Valsiner e Vygotsky sobre a mediação semiótica, nos quais os signos funcionariam, sucessivamente, para gerar contextos-específicos de fenômenos psicológicos (Komatsu, 2010).
Os aspectos teóricos de sua proposta enfatizam uma visão do Self como uma entidade dinâmica, que emerge na relação do sujeito com seu entorno imediato, e não como uma entidade interna, que é possível de ser revelada quando se pergunta diretamente por ela com o uso de questionários e outros testes. Nessa relação, o Self presentacional pode ser percebido pela pessoa, ou por um observador, sem a necessidade de uma fala. A emergência do Self se evidenciaria a partir da observação de sequências organizadas de interações do sujeito com outras pessoas (e objetos).

Com relação aos aspectos metodológicos da pesquisa, o autor investigou, particularmente, as conversas entre mãe-criança, quando ambas retornam do jardim de infância (hoikuen ou yochienem japonês) para casa. Tais conversas foram registradas através de gravações, pelo período de um ano escolar. Na pesquisa, uma criança (entre 4 e 5anos) e sua mãe foram gravadas em áudio (a mãe foi instruída pelo pesquisador, para realizar a gravação), em um ambiente completamente natural, no caminho do jardim de infância para casa. Nessas conversas, predominavam temas referentes a experiências da criança no ambiente escolar.

Os episódios para análise foram selecionados a partir de três tópicos fundamentais: (1) atividades nas quais a criança participava no ambiente escolar, incluindo alguns comportamentos específicos; (2) observações da criança, incluindo os nomes, características ou comportamentos de seus amigos ou professores; e (3) regras e horários. Os resultados mostram como o Self emerge a partir de um processo semioticamente mediado de diferenciação na conversa. A criança não apenas se posiciona na conversação, mas começa a construir o repertório de seus selves em relação a outras pessoas, e cada vez é mais consciente desse repertório. A conversa se torna, então, mais destacada econsciente para a criança. A linha de desenvolvimento de conversas do mesmo tipo, entre mãe-criança, demonstra uma evolução gradual nos posicionamentos da criança, os quais se apresentam cada vez mais estáveis.

Estudos que enfatizam a narrativa como uma ferramenta na autocompreensão das crianças também são levados em consideração para as análises sobre o Self (Bellgard, 2005; DeSocio, 2005; Ochs \& Capps, 1996; Uszynska-Jarmoc, 2008). Na pesquisa apresentada por Bellgard (2005), são analisadas as capacidades das crianças de 5 anos, para a construção de narrativas "coerentes" que fazem referência ao Self. Os procedimentos desenvolvidos pela autora foram: (1) Questionário enviado para os pais,em que se perguntava sobre figuras importantes na vida das crianças e acontecimentos relevantes recentes. Também havia questões sobre a composição familiar e atividades frequentes das crianças. (2) A criança foi convidada a elaborar um livro de histórias junto com o pesquisador, levando em consideração os elementos reportados pelos pais. Para a construção do livro, a pesquisadora definiu cinco tipos de histórias a serem contadas: 1) sobre a família; 2) sobre algum evento significativo comentado pelos pais; 3) sobre irmãos ou amigos (relacional); 4) sobre um dia no qual se sentiu muito zangada; e 5) sobre o que gostaria de ser quando crescer.

As análises do livro de histórias focalizaram as possibilidades de as crianças construírem relatos coerentes. Os elementos dessas análises foram: quem, o que, por que, 
como, onde e quando. A partir do destaque desses elementos, Bellgard (2005) categorizou as histórias das crianças como: (1) não histórias (11\% das crianças), (2) incoerentes (14\% das crianças), (3) coerentes básicas (37,5\% das crianças) e (4) coerentes $(37,5 \%$ das crianças).

A discussão da autora se concentrou, principalmente, em assinalar que: (1) cinco das sete crianças conseguiram produzir histórias coerentes, pelo menos a maioria das vezes; (2) as crianças conseguiram refletir sobre elas mesmas e dar sentido aos seus mundos; e que (3) existe uma necessidade de criar métodos para acessar a reflexão das crianças sobre elas mesmas. Para finalizar, a pesquisadora destacou que as crianças pequenas devem ser entendidas, não como pessoas passivas, incapazes de se autoconhecer, mas como agentes ativos, que são seres autores de suas vidas. Portanto, as possibilidades das crianças para assumir um ponto de vista na narrativa, expressão de um Self, seriam indicadores de autoconsciência.

O estudo de Bellgard (2005) é um exemplo de como a maioria das pesquisas com narrativas abordam a problemática do Self. Os elementos levados em consideração, pela autora, centram-se na estrutura narrativa dos relatos e ignoram o papel da cultura nas suas análises. Outros estudos com crianças mais velhas vão mostrar características similares.

Em uma pesquisa com crianças entre 6 e 7 anos, UszynskaJarmoc (2008) aborda, principalmente, os conceitos de "autoestima" e "autoconhecimento". Na sua pesquisa, destaca a importância de analisar o conteúdo da narrativa das crianças sobre elas mesmas, para evidenciar o conceito de Self. Em sua perspectiva, a autoavaliação ou autodescrição feita pela criança pode não ser apenas informativa sobre sua aparência física, mas também informa sobre avaliações psicológicas de si mesma.O estudo foi desenvolvido com 31 crianças no ambiente escolar. As ferramentas metodológicas usadas pela pesquisadora consistiram em: (1) gravações de vídeo das entrevistas semiestruturadas com as crianças encaminhadas à análise de autodescrição; (2) análises do desenho do autorretrato feito pela criança, e (3) dois questionários sobre autoestima.

As análises foram feitas inter-relacionando todos esses procedimentos de pesquisa, focados, principalmente, nas suas narrativas. As narrativas das crianças foram classificadas por categorias relacionadas aos tópicos de autodescrição e autoconhecimento. Elas foram definidas como: (1) atividades - por exemplo, vou caminhar, brincar etc -; (2) dados pessoais; (3) preferências - eu gosto de... -; (4) emoções; (5) posses - eu tenho... -; (6) comportamento social; (7) aparência física; (8) experiências passadas; em menor grau, (9) sonhos e planos; (10) caraterísticas de temperamento; (11) saúde; e (12) competência escolar.

Segundo Uszynska-Jarmoc (2008), os resultados do estudo confirmam a legitimidade das ferramentas utilizadas para explorar as diferentes configurações de Self feitas pelas crianças. Igualmente, a autora destaca o fato de conseguir desvendar o conceito de Self representado na mente das crianças, e as suas possibilidades de comunicá-lo através da narrativa. Dessa maneira, para a pesquisadora, o Self é expresso por meio da autoapresentação.

Outra pesquisa mais recente, com crianças de 7 anos, foi desenvolvida por van Doornevan Nijnatten (2012). Eles se concentraram no estudo do Self dialógico em psicoterapia e realizaram uma adaptação para crianças do método de Self-confrontação de Hermans (2001). Os procedimentos desenvolvidos em psicoterapia estavam direcionados por uma tomada de consciência, por parte da criança e de suas posições de Eu. Para isso, vários procedimentos desenvolviam-se incluindo a decisão da criança sobre como desenvolver a sessão de terapia. Segundo os autores, essa decisão feita pela criança já se configura em uma posição do Eu. Posteriormente, o terapeuta fazia a sessão, tal como o combinado, com a criança. Quando a sessão terminava, o terapeuta pedia para a criança planejar a próxima sessão e trazer algum material de casa, como fotos ou outros objetos que a criança tivesse vontade de compartilhar na terapia.

Seguindo a estrutura anterior, na sessão, o terapeuta começava a confrontar a criança em direção a uma construção de posições de Eu. Segundo os autores, essas posições são construídas, porque: (1) a criança está ciente de que há escolhas a serem feitas e estão ligadas a realidades físicas; (2) a criança é tratada como alguém com diferentes preferências pessoais (posições de Eu), que podem mudar; e (3) a consciência de diferentes posições de Eu tornam-se experienciais, na medida em que o terapeuta assinala diversas emoções e confronta a criança. Segundo os autores, por meio de conversas sobre a vida cotidiana das crianças, é possível identificar suas posições de Eu. A interação com o terapeuta permite que a criança se acostume a falar sobre seus próprios sentimentos e estados psicológicos.

\section{Panorama dos estudos de dois aos sete anos}

Nos parágrafos anteriores, fizemos algumas descrições de pesquisas sobre o Self, algumas delas, especificamente, sobre o desenvolvimento do Self dialógico. É claro que existem outros estudos que trabalham sobre essa matéria, no entanto, tivemos acesso apenas aos anteriores. Algumas dificuldades ou lacunas foram identificadas, como, por exemplo, poucos estudos realizados em contextos escolares com crianças (crianças de 5 a 6 anos, aproximadamente). Além disso, a maioria das descrições estão focadas na narrativa das crianças, sem que o pesquisador tenha acesso a outros indicadores que informem sobre o desenvolvimento. Os enfoques teórico-metodológicos, nesses trabalhos,também não esclarecem o papel da cultura e estudam a criança de maneira isolada, mesmo estando em instituições educativas. Vemos, igualmente, que os estudos realizados com crianças maiores de 2 anos de idade enfatizam as limitações cognitivas/representacionais das crianças antes dos 7 anos. Sendo assim, estudos que integrem as diferentes dimensões da criança e os diferentes contextos culturais, como escola e família, estão praticamente ausentes. O que mais chama a atenção é como aspectos emocionais e afetivos não são levados em conta nas pesquisas, uma vez que, para vários teóricos (Branco, 2012; Valsiner, 2014), o caráter central do desenvolvimento do Self dialógico é de natureza afetiva. 


\section{Considerações Finais}

Para estudar o desenvolvimento infantil, tomando como ponto de partida a Teoria do Self Dialógico, é preciso levar em consideração as interações dialógicas, as quais acontecem desde muito cedo. Alguns autores afirmam, inclusive, que, quando o bebê nasce, já se encontra em um ambiente dialógico, o qual seria a base para o desenvolvimento do Self. Estudos recentes convidam a uma transformação de paradigma, em que um "Eu" autocontido ceda lugar a um Self relacional, no qual o desenvolvimento e a mudança são contingentes na alteridade (Bertau et al., 2012).Os aspectos teóricos da maioria das pesquisas retomam a TSD com outras propostas, como a teoria dos sistemas dinâmicos e a abordagem cultural, e os estudos realizados com crianças antes dos 2 anos parecem apresentar maior clareza quanto ao embasamento teórico (Lyra, 2010).

A grande maioria das pesquisas revisadas para este artigo ressalta a importância de metodologias qualitativas com o uso do método microgenético, e este método permite o seguimento das interações mãe-bebê com vistas ao descobrimento da emergência de padrões dialógicos. No entanto, essa orientação não está tão presente nos trabalhos com crianças entre 2 e 7 anos, pois esses trabalhos não utilizam metodologias que analisam as sequências interativas em maior detalhe, como acontece com as de orientação microgenética. Contudo, os trabalhos recentes de Roncacio-Moreno (2015) e Roncancio-Moreno e Branco (2014) propõem uma abordagem ampla dos processos de desenvolvimento do Self dialógico desde uma perspectiva sociocultural utilizando essas metodologias microgenéticas no contexto da escola e da família.

Consideramos, assim, que existem importantes avanços na pesquisa dos primeiros 2 anos de vida, mas encontramos lacunas no que se refere ao desenvolvimento do Self posterior a essa faixa etária, levando em conta sua complexidade dinâmica e, sobretudo, sua contextualização. Daí a necessidade de investigações sobre os processos envolvidos no desenvolvimento do Self nas crianças,em diferentes momentos e contextos socioculturais.

Sugerimos pesquisas preocupadas com a ontogênese do Self (Roncacio-Moreno, 2015; ) e Roncancio-Moreno \& Branco, 2014), que integrem os processos complexos e dinâmicos do desenvolvimento humano, caracterizados pela imprevisibilidade e mudança. Pesquisas que permitam o seguimento no tempo das transformações nas crianças e que outorguem a elas a possibilidade de se expressar, o que levaria à melhor compreensão da trajetória de vida dos sujeitos, também são sugeridas. Igualmente, precisamos de estudos que se dediquem à dinâmica do Self em diferentes idades, indagando sobre as possíveis tensões e ambivalências presentes desde muito cedo no desenvolvimento.

\section{Referências}

Andacht, F., \& Michel, M. (2005). A semiotic reflection on selfinterpretation and identity. Theory \& Psychology, 15(1), 51-75.

Bellgard, T. (2005). Examining "Self” in Five-Year-Olds'Personal Stories: A Narrative Analysis of Coherence. Retrieved from http://psych.hanover.edu/research/thesis07/bellgardpaper.pdf
Bennett, M., \& Sani, F. (2004). The development of the social self. New York: Psychology Press.

Bertau, M. C. (2004). Developmental origins of the dialogical self: some significant moments. In H. Hermans \& G. Dimaggio (Eds.), The dialogical self in psychotherapy (pp. 29-42). New York: Brunner-Routledge.

Bertau, M. C. (2007). On the notion of voice: An exploration from a psycholinguistic perspective with developmental implications. International Journal for Dialogical Science, 2(1), 133-161.

Bertau, M. C. (2012). Exploring voice: A psycholinguist's inquiry into the dynamic materiality of language. In M. C. Bertau, M. M. Gonçalves, \& P. T. F. Raggatt (Eds.), Dialogic formations: Investigations into the origins and development of the dialogical self (pp. 41-68). Charlotte, NC: Information Age Publishers.

Bertau, M. C., \& Gonçalves, M. (2007). Looking at "meaning as movement" in development: Introductory reflections on the developmental origins of the dialogical self. International Journal for Dialogical Science, 2(1), 1-13.

Bertau, M. C., Gonçalves, M. M., \& Raggat, P. (2012). Dialogic formations: Investigations into the origins and development of the dialogical self. Charlotte, NC: Information Age Publishing.

Branco, A. U. (2010, october). Dialogical self conceptualizations along the dynamics of cultural canalizations processes of self development. Paper presented at the Sixth Dialogical Self Conference, Athens, Greece.

Branco, A. U. (2012). Metacommunication, microgenesis, and ideographic science: The study of meaning-construction processes. In S. Salvatore, A. Gennaro \& J. Valsiner (Eds.), Making sense of infinite uniqueness (pp. 109-132). Charlotte, NC: Information Age Publishing.

Branco, A. U., \& Madureira, A. (2008). Dialogical self in action: The emergence of self-positions among complex emotional and cultural dimensions. Estudios de Psicología, 29(3), 319-332.

Cunha, C., Salgado, J., \& Gonçalves, M. (2012). The dialogical self in movement: Narrating a method to capture the dynamics of change and stability in the self. In E. Abbey \& S. Surgan (Eds.), Developing methods in psychology (pp. 65-100). New Brunswick, NJ: Transaction Publishers.

DeSocio, J. E. (2005). Accessing self-development through narrative approaches in child and adolescent psychotherapy. Journal of Child and Adolescent Psychiatric Nursing, 18(2), 53-61.

Fogel, A. (1993). Developing through relationships: Origins of communication, self, and culture. Chicago, IL: University of Chicago Press.

Fogel, A., \&Garvey, A. P. (2007). Alive communication. Infant Behavior and Development, 30, 251-257.

Fogel, A., de Koeyer, I., Bellagamba, F., \& Bell, H. (2002). The dialogical self in the first two years of life: Embarking on a journey of discovery. Theory and Psychology, 12, 191-205.

Freire, S. (2008). Concepções Dinâmicas de Si de crianças em escolarização: uma perspectiva dialógico-desenvolvimental. (Unpublished doctor dissertation) Universidade de Brasília, Brasília.

Garvey, A., \& Fogel, A. (2007). Dialogical change processes, emotions, and the early emergence of self. International Journal for Dialogical Science, 2(1), 51-76. 
Gonçalves, M., \& Ribeiro, A. (2012). Narrative processes of innovation and stability within the dialogical self. In H. J. M. Hermans\& T. Gieser (Eds.), Handbook of dialogical self theory (pp. 310-318). Cambridge: Cambridge University Press.

Gratier, M., \& Bertau, M. C. (2012). Polyphony: A vivid source of self and symbol. In M. C. Bertau, M. M. Gonçalves, \& P. T. F. Raggatt (Eds.), Dialogic Formations: Investigations into the origins and development of the dialogical self (pp. 85-119). Charlotte, NC: Information Age Publishers.

Harter, S. (1999).The construction of the self: A developmental perspective. New York: The Gilford Press.

Hermans, H. (2001). The dialogical self: Toward a theory of personal and cultural positioning. Culture \& Psychology, 7, 243-281.

Hermans, H. (2003). The construction and reconstruction of a dialogical self. Journal of Constructivist Psychology, 16, 89-130.

Hermans, H., \& Hermans-Konopka, A. (2010). Dialogical self theory: Positioning and counter-positioning in a globalizing society. New York: Cambridge University Press.

Hermans, H., \&Kempen, H.J.G. (1993). The dialogical self: Meaning as movement. San Diego, CA: Academic Press.

Komatsu, K. (2010). Emergence of young children's presentational self in daily conversation and its semiotic foundation. Human Development, 53, 208-228.

Komatsu, K. (2012). Temporal reticence of the self: who can know my self? Integrative Psychological and Behavioral Science, 46, 357-372.

Lima DeSouza, M., Oliveira, M., DaSilveira, M., \& Gomes, W. (2013). A lógica da dialogicidade narrativa no repertório de posições pessoais. Psicologia: Teoria e Pesquisa, 29(3), 321-329.

Lopes de Oliveira, M. C. S. (2013). The baktinian self and beyond: Towards a dialogical phenomenology of the self. Culture \& Psychology, 19, 259-272.

Lyra, M. C. D. P. (2006). O modelo EEA para a investigação da emergência e desenvolvimento da comunicação e do self: bases conceituais e fundamentos teórico-metodológicos. Estudos de Psicologia, 11(1), 25-33

Lyra, M. C. D. P. (2007). O modelo EEA: definições, unidade de análise e possíveis aplicações. Psicologia, Reflexão e Critica, 20(1), 87-95.

Lyra, M. C. D. P. (2010). On interaction analysis and dialogical perspective: Emergent patterns of order and relational agency. Integrative Psychological and Behavioral Science, 44, 273280.

Maratos, O. (1973). The origin and the development of imitation during the first six months of life. (Unpublished doctor dissertation), Geneva University, Suíça.

Mattos, E. \& Chaves, A. (2013). The architecture of self-in-motion: Exploring young people's construction of "becoming". Interacções, 24, 106-136.

Mead, G. H. (1934). Mind, self, and society. Chicago, IL: University of Chicago Press.

Meltzoff, A. N., \& Moore, M. K. (1994). Imitation, memory, and the representation of persons. Infant Behavior and Development, 17, 83-99.

Nagy, E., \& Molnar, P. (2004). Homo imitansor homo provocans? The phenomenon of neonatal initiation. Infant Behaviour Development, 27, 57-63.
Nelson, K. (1992). Emergence of autobiographical memory at age 4. Human Development, 35(3), 172-177.

Ochs, E., \& Capps, L. (1996). Narrating the self. Annual Review of Anthropology, 25, 19-43.

Rochat, P. (2003). Five levels of self-awareness as they unfold early in life. Consciousness and Cognition, 12, 717-731.

Rodriguez, C. (2006). Del ritmo al símbolo. Los signos en el nacimiento de la inteligencia. Barcelona: Horsori.

Roncancio-Moreno, M. (2015). Dinâmica das significações de si em crianças na perspectiva dialógico-cultural (Unpublished doctoral dissertation) Universidade de Brasília, Brasília.

Roncancio-Moreno, M., \& Branco, A. (2014). Desenvolvimento das significações de si na perspectiva dialógico-cultural: um estudo de caso. Revista Psicologia em Estudo, 19(4), 599-610.

Rosa, C., \& Gonçalves, M. (2013). Estratégias dialógicas de autoorganização da identidade: psicoterapia e reestruturação da gestão interna. Psicologia: Teoria e Pesquisa, 29(3), 305-312.

Salgado, J., \& Gonçalves, M. (2007). The dialogical self: Social, personal and (un)conscious. In J. Valsiner\& A. Rosa (Eds.), The Cambridge Handbook of Sociocultural Psychology (pp. 608-621). New York: Cambridge University Press.

Santos, M., \& Gomes, W. (2010). Self dialógico: teoria e pesquisa. Psicologia em Estudo, 15(2), 353-361.

Simão, L. (2010). Ensaios Dialógicos: compartilhamento e diferença nas relações eu-outro. São Paulo: HUCITEC.

Thelen, E., \& Smith, L. B. (1994). A dynamic systems approach to the development of cognition and action. Cambridge, MA: Bradford Books/MIT Press.

Trevarthen, C. (2012). The infant's voice grows in intimate dialogue: How musicality of expression inspires shared meaning. In Marie-CécileBertau, Miguel M. Gonçalves, M. \&Peter T. F. Raggatt (Eds.) Dialogic formations: Investigations into the origins of the Dialogical Self (pp. 3-40). Charlotte NC: Information Age Publishing.

Tomasello, M. (1993). On the interpersonal origins of selfconcept. In U. Neisser (Ed.), The perceived Self: Ecological and interpersonal sources of self-knowledge (pp. 174-184). Cambridge University Press.

Uszynska-Jarmoc, J. (2008). The child's conception of selfknowledge and self-esteem. International Views on Early Childhood Education, 1-16.

Valsiner, J. (2007). Culture in minds and societies: Foundations of cultural psychology. New Delhi: Sage.

Valsiner, J. (2014). An invitation to cultural psychology. Londres: Sage.

van Doorn, F., \& van Nijnatten, J. (2012). How about you? Building blocks for a dialogical self therapy for children. International Journal for Dialogical Science, 6(1), 15-29.

Wallon, H. (1987). Psicología y educación del niño. Una comprensión dialéctica del desarrollo y la Educación Infantil. Madri: Visor-Mec.

Recebido em 13.12.2013

Primeira decisão editorial em 11.12.2014

Versão final em 05.01.2015

Aceito em 12/05/2015 